\title{
Termalismo y hábitat en el Valle Medio del Ebro en época antigua
}

\author{
María Jesús Peréx Agorreta* \\ Mercedes UnzU URMENETA**
}

A la hora de establecer el comienzo en la utilizaciòn de las aguas mineromedicinales y/o termales con fines curativos, nos encontramos, en la zona que nos ocupa, con una falta casi absoluta de datos referidos a épocas prerromanas.

En los balnearios conocidos ${ }^{1}$, cuyas primeras construcciones datan, en la mayoría de los casos, del siglo XIX, no se han llevado a cabo prospecciones y menos aún, campañas de excavación ${ }^{2}$. De aqui se deduce la necesidad de realizar estudios completos de todos los balnearios y fuentes en los que todavía es posible.

A título de hipótesis, proponemos establecer una primera relación entre los manantiales mineromedicinales y/o termales y los asentamientos atestiguados en sus proximidades, que en algunos casos, como en Echauri, podrian remontarse al Paleolítico ${ }^{3}$. No obstante, los testimonios más abundantes corresponden a la Edad del Bronce y, sobre todo, a la Edad del Hierro.

* UNED, Madrid.

** Museo de Navarra, Pamplona.

"URKIA, J. M., "Balnearios y fuentes minero-medicinales de Navarra», en Ibaiak eta Haranak. San Sebastián, Etor, 1988, tomo 7, págs. 213-224.

Zubiaur, J. A., "El agua en la Historia: época Medieval y Moderna", en El agua de $\mathrm{Na}-$ varra. Pamplona, Caja de Ahorros de Navarra, 1991, págs. 28-31.

${ }^{2}$ A excepción de los Baños de Fitero, donde las obras de remodelación de los Baños Viejos (hoy Balneario Hotel Palafox) en 1982, tuvieron como consecuencia la desaparición de trece de los catorce baños o pozos de época romana.

Medrano, M. M., y Diaz, M. A., "Las instalaciones balnearias romanas de Fitero", Príncipe de Viana, Anejo 7. Pamplona 1987, págs. 491-501 (A partir de aquí $P V$ ).

${ }^{3}$ Barandiaran, I. y Vallespl, E., "Prehistoria de Navarra", Trabajos de Arqueología Navarra, 2. Pamplona 1980, pág. 110 (a partir de aquí TAN). 
En esta región del Alto Valle Medio del Ebro podemos destacar tres zonas: Ia montaña de Navarra, la cuenca de Pamplona y el somontano riojano [lámina 1].

\section{MONTAÑA DE NAVARRA}

En ella se localizan cuatro balnearios, ninguno de los cuales se halla abierto en la actualidad. Son los de Elgorriaga, Betelu, Alsasua y Arive.

El manantial medicinal de Elgorriaga se descubrió, como tantos otros, casualmente, tras observar la querencia de los animales a pastar en un prado junto al río Ezcurra. Se estudió el terreno y encontraron un yacimiento salino, que se explotó para la obtención de sal desde mediados del siglo pasado. En 1902 se construyó un edificio balneario que fue cerrado en 1955. Sus aguas son clorurosódicas, frías, bromoyoduradas, de fuerte mineralización ${ }^{4}$.

Betelu destaca por su gran riqueza hidromineral. Próximos a la población existen cuatro manantiales termominerales conocidos con los nombre de Dama Iturri (Fuente de la Señora), Iturri Santu (Fuente Santa), Urberoa (agua caliente) y Carmelo. Son aguas clorurosódicas, bicarbonatadas y sulfurosas.

La primera instalación de baños data de 1798 , de la que no queda nada en la actualidad. Sus aguas se embotellan desde 1882, existiendo hoy en dia únicamente la planta embotelladora ${ }^{5}$.

En Alsasua fue descubierto, hacia 1825, un manantial sulfuroso que, a partir de 1869 se explotó como centro balneario, hasta 1920, en que fué clausurado. La fuente, conocida como Iturri Bendicatu (Fuente bendita) o también Fuente de la Salud, sigue siendo utilizada por los vecinos del lugar ${ }^{6}$.

La fuente medicinal de Arive era conocida en el siglo xvIII. El balneario fue construido a mediados del siglo pasado, llegando su uso hasta los años veinte del presente siglo. Sus aguas son ferruginosas y carbonatadas. Hoy queda el edificio abandonado y el topónimo Iturri ${ }^{7}$.

4 Zubiaur, J. A., op. cit, pág. 30.

5 Ibidem, págs. 29-30.

${ }^{6}$ Ibidem, pág. 29.

7 Ibidem, pág. 29. 


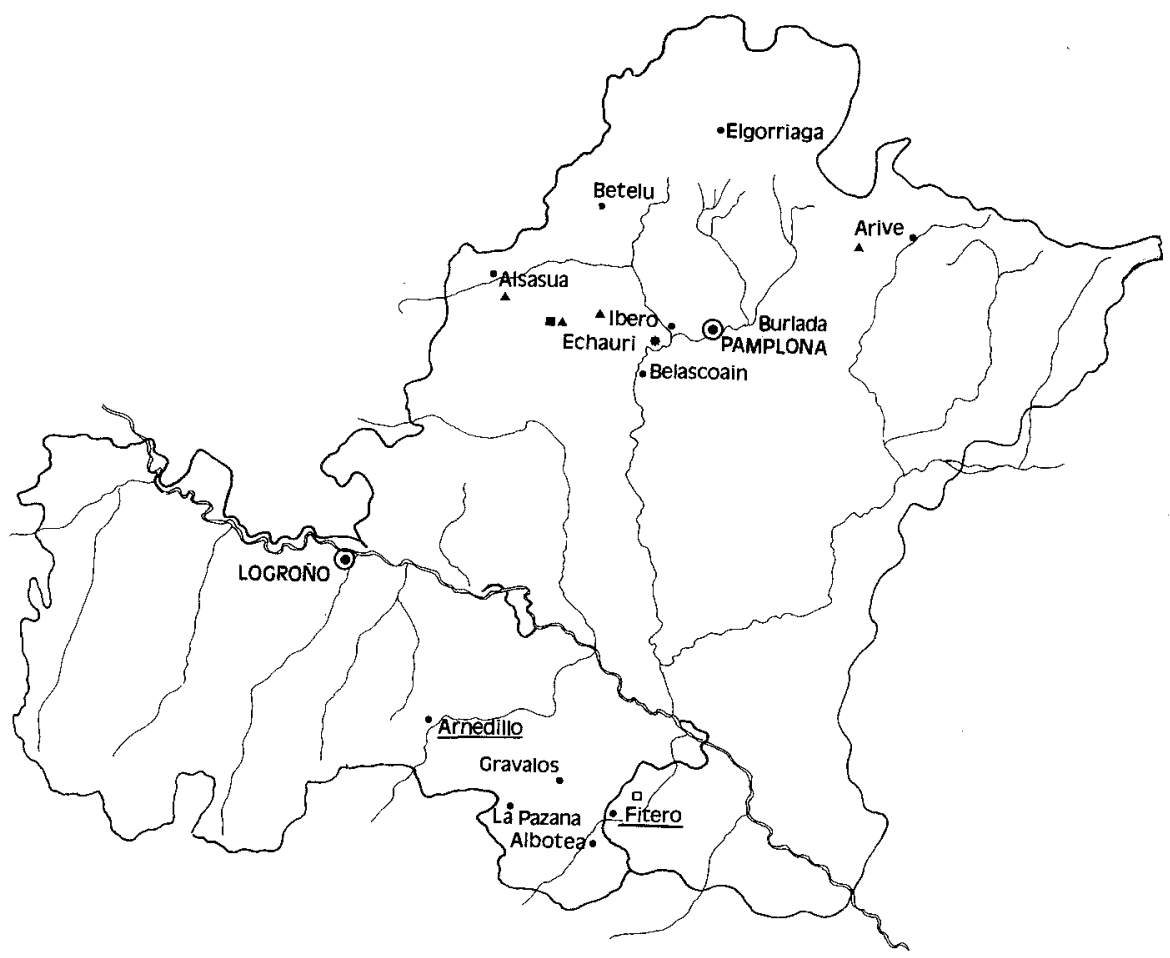

Lám. 1. Yacimientos y hallazgos asociados a manantiales mineromedicinales y/o termales, en Navarra y La Rioja.

En ninguno de estos cuatro manantiales se han realizado prospecciones ni hay noticias que hagan referencia a hallazgos casuales en el momento de la construcción o remodelación de los balnearios.

No obstante, todos ellos se encuentran en zonas que, aunque no han estado nunca excesivamente pobladas, hay vestigios que se remontan hasta el Neolítico, como en las cuevas de Atabo y Coscobilo (en Alsasua) y Aizpea (en Arive). En la cueva de Atabo se superponen niveles pertenecientes al Neolítico y a la Edad del Bronce, del mismo modo que en la de Aizpea.

En relación a estas épocas de la Prehistoria en el Pirineo Occidental, que abarcarian desde, aproximadamente, el 4.500 al 1.000 (Neolítico, Eneolítico y Edad del Bronce) no puede hablarse de etapas culturales bien diferenciadas, ni de que tuviera lugar la conocida como «revolución neo- 
lítica", sino que más bien se trata de una continuidad cultural en la que a las formas de la vida del Paleolítico-Epipaleolítico se añaden las innovaciones propias del Neolítico, para continuar hasta la plena Edad del Bronce ${ }^{8}$. De ahí la dificultad en establecer una separación cronológica tajante referida a las construcciones que, en un sentido amplio, entrarían dentro del concepto megalítico: cámaras sepulcrales (dólmenes), círculos de piedras (cromlechs), monolitos exentos (menhires) y amontonamientos de piedras menores y de tierra (túmulos). Podríamos hablar de dólmenes dentro de un contexto Neolítico Final-Eneolítico y del Bronce Medio, mientras que los cromlechs deben fecharse en el Bronce Final o en la plena Edad del Hierro ${ }^{9}$.

Estas manifestaciones de carácter funerario se localizan en todas las zonas del Pirineo Occidental y corresponden a grupos pastoriles que practican la trashumancia y que depositan a sus difuntos en dólmenes, bajo túmulos o en el interior de los cromlechs, en las mismas zonas de pastos que frecuentan.

En la Sierra de Aralar (al noroeste de Navarra), al norte de la cual se halla Betelu, y al sur, Alsasua, se localizan seis sectores dolménicos: Aratz-Alsasua, con dos dólmenes; Altzania, con trece; Ataun-Burunda, con catorce; Aralar, con sesenta y uno; Larraun con once y Araiz con uno. Además del sector de Gorriti-Huici, con tres dólmenes, junto a Betelu ${ }^{10}$.

La existencia de tan elevado número de construcciones funerarias es un exponente de los movimientos periódicos de trashumancia pastoril. Los lugares de habitación serían, según los ritmos anuales de la trashumancia, en abrigos y cuevas próximas a las majadas o en construcciones no muy duraderas, como chozas o cabañas.

Todo hace suponer que estos pastores conocerían los manantiales de Alsasua y Betelu, que se encontraban en la zona de paso a los pastos de alta montaña, y que tanto ellos como sus ganados se beneficiarian de sus propiedades salutíferas. No debemos olvidar que, como ya se ha dicho más arriba, han sido los animales quienes, en numerosísimas ocasiones, han preferido las aguas de estos manantiales a las de los ríos próximos a ellos.

Al este de Elgorriaga se hallan dos sectores: el de Bertiz-Arana, con tres dólmenes, y el de Legarte o Lerate, con doce.

\footnotetext{
"SAnchez, A. C., y UnzU, M., "Prehistoria y Edad del Hierro", Panorama, 2. Pamplona 1986, págs. 22-23.

9 Barandiaran, I., y Vallespi, E., op. cit., pág. 143.

${ }^{10}$ Ibidem, págs. 147-148 y 155.
} 
También Arive se encuentra en el paso obligado a las zonas de pastos de alta montaña, en las que se encuentran el sector de Orbaiceta, con ocho dólmenes, y el de la sierra de Abodi, con diez, que constituye la estación con ejemplares a mayor altitud de todo el repertorio dolménico pirenaico (superando los 1.400 metros).

Al noroeste de Arive, existen otros dos importantes sectores: el de Erro, con once dólmenes y un túmulo, y el de Urepel-lbañeta, con, al menos, doce dólmenes y cuatro estructuras tumulares ${ }^{11}$.

Se da la circunstancia de que es también aquí donde se encuentra una de las mayores concentraciones de cromlechs y menhires, que según las últimas investigacioens, se corresponden con la Primera Edad del Hierro ${ }^{12}$.

\section{CUENCA DE PAMPLONA}

Vienen a continuación los principales manantiales situados en la llamada cuenca de Pamplona. Se trata de los siguientes: Burlada, Ibero, Echauri y Belascoain.

En la primera, junto a Pamplona, se descubrió, en 1872, una fuente de aguas alcalinas, salinas, bicarbonatado-sódicas y yoduradas. Los arrieros que hacian noche en la venta la bebian, notanto alivio en sus dolencias gástricas. En las antiguas ventas se construyó el edificio balneario que fue abandonado en 1939. En la actualidad sólo queda su recuerdo en la calle de La Fuente ${ }^{13}$.

En Ibero hay dos surgimientos: Ia fuente de Iturricoa lbero y junto a ella, el de Uberba (agua caliente) que brota en el fondo de un estanque. Junto a éste estuvo el edificio balneario, construido en 1866, que se mantuvo en uso hasta finales de siglo. Sus aguas son cloruradas-sódico-cálcicas y tienen las mismas caracteristicas y propiedades que las de Echauri y Belascoain, por lo que se consideran procedentes del mismo manantial, cuyas aguas afloran en tres lugares distintos ${ }^{14}$.

11 Ibidem, pág. 156.

${ }^{12}$ ibidem, págs. 223-228.

${ }^{13}$ Zabiaur, J. A., Op. cit., pág. 30, y VVAA, Aguas minero-medicinales de España. Madrid 1903, págs. 73-79.

${ }^{14}$ En la actualidad los vecinos de Ibero todavía utilizan la fuente, y el agua del estanque se sigue empleando para mover un molino harinero. URKıA, J. M., op. cit., pág. 224. 
En Echauri no se conoce que haya existido nunca un balneario y sin embargo hay un manantial que, como en lbero, surge en el fondo de un estanque ${ }^{15}$.

Al pie de Belascoain, y junto al río Arga, en el lugar conocido como «Arrabal del agua caliente», brotan dos fuentes cuyas propiedades ya se conocian en el siglo xvill. Se trata de un manantial termomineral $\left(26^{\circ}\right)$ que drena el acuifero de Ibero-Echauri y surge en las margas del Eoceno, a través de una falla, posiblemente originada por el diapiro de Salinas de Oro ${ }^{16}$.

Son aguas bicarbonatadas-cloruradas-sodicocálcicas. El edificio balneario data de 1831, aunque un siglo después su estado es de abandono ${ }^{17}$.

En torno a Ibero-Echauri-Belascoain se encuentra la zona más poblada de la cuenca de Pamplona durante la Edad del Hierro. No obstante, su poblamiento se remonta al Paleolítico Medio, durante el cual bandas de cazadores ocuparon el raso de la Sierra de Urbasa. Hasta el momento se han localizado veinte lugares de concentración de hallazgos, pertenecientes a la categoría de "yacimientos al aire libre», sin depósito estratificado. Se trata, en la mayoría de los casos, de restos de taller en los que se han recuperado nódulos, núcleos, lascas y numerosas piezas, como bifaces, endedores, discos, raederas, raspadores, etcétera ${ }^{18}$.

Más concretamente, en Echauri, se ha localizado un conjunto al aire libre cuya riquísima industria de silex ha sido atribuida al Magdaleniense ${ }^{19}$, y que podría interpretarse como un campamento temporal de verano en un recodo del río Arga, próximo al manantial termal ${ }^{20}$.

A un momento indeterminado, entre el Eneolítico y la Edad del Bronce, corresponden las cuevas y covachos del término de Echauri. También de la zona de Leguín (junto a Echauri) se conocen varios covachos con enterramientos de inhumación y ajuares, que han sido destruidos.

Destacan dos yacimientos: la cueva del Muro y el abrigo del Cantero. De la primera proceden tres fragmentos de pared de vaso campaniforme

${ }^{15}$ Y que también servía para mover un molino, hoy en ruinas.

16 Zubiaur, J. M., op. cit., pág. 29.

17 En la actualidad se ha reconstruido el edificio, la fuente y los jardines que lo rodean, pero no está en uso. Existe una planta embotelladora.

18 Barandiaran, I. y Vallespi, E., op. cit., págs. 80-88.

19 Ibidem, págs. 110 y 123.

${ }^{20}$ Para el poblamiento durante el período Neolítico, Eneolítico-Bronce, ver VALLESPI, E., «Hipótesis de trabajo sobre el sustrato arqueológico de la romanización del País Vasco meridional (Álava y Navarra)", Estudios de Deusto, 20. Bilbao 1972, págs. 241-250; y BARANDIARAN, I. Y VALLESPI, E., op. cit., págs. 129-132. 
(de tipo marítimo o internacional), un punzón de bronce, dos botones en hueso (tipo Durfort), una plaqueta pulimentada con perforación en un extremo y dos láminas de silex sin retocar ${ }^{21}$.

En el abrigo del Cantero se han localizado tres figuras de pequeño tamaño, de color ocre, que presentan una cabra (de unos $8 \mathrm{~cm}$ de largo), un cuadrúpedo (quizá otra cabra) y una figura humana (de unos $13 \mathrm{~cm}$ de alto). Es difícil establecer su cronología. Se incluye dentro de la «pintura esquemática", con una datación que puede situarse a partir del Eneolítico, perdurando a lo largo de la Edad del Bronce ${ }^{22}$.

Es precisamente en el término de Echauri donde se han localizado y excavado, tres poblados: San Quiriaco, Leguín y Santo Tomás, pertenecientes a la Edad del Hierro. El material recuperado más frecuente lo constituyen numerosos fragmentos de cerámica hecha a mano, de superficies rugosas, con decoración aplicada debajo del borde (cordón, digitales, incisa de círculos y triángulos). Algunas superficies aparecen peinadas y otras, las menos, pulidas ${ }^{23}$.

En el Museo de Navarra se halla depositado un lote de piezas metálicas procedentes de Echauri, de las que se desconocen el lugar exacto de procedencia y las circunstancias del hallazgo. No obstante, la mayoría han podido ser identificadas como armas (espada de antenas, espada de larga espiga tipo La Tène I, punta de lanza con nervio central tipo La Tène II, punta de jabalina, punta de flecha...) y herramientas (reja de arado, azuela, escardillo, cuchillo, cincel...), además de un freno de caballo y una abrazadera de escudo ${ }^{24}$.

Debemos destacar la existencia de varias sepulturas de inhumación, tres de ellas en Santo Tomás (una infantil) y otra en Leguin Chiqui (también infantil). Esto indica una perduración del rito propio de la Edad del Bronce dentro de un contexto cultural correspondiente a la Edad del Hierro (casas, cerámicas, piezas metáicas), que se caracterizó por la introducción y generalización del ritual de la incineración.

Algunos fragmentos de cerámica a torno celtibérica confirman la perduración del poblamiento hasta el Hierro II, e incluso la época romana,

${ }^{21}$ lbidem, págs. $139-140$.

22 Ibidem, págs. 185-186. Se ha encontrado en el abrido de Lasierreka, Echauri, una laja de caliza con signos pintados, también de estilo esquemático, perteneciente al NeolíticoBronce, Sánchez, A. C. y Unzu, M., op. cit., pág. 55. Armendariz, R. M., et alii, "Nuevas pinturas esquemáticas en el término de Echauri (Navarra)", PV Anejo 7, 1987, págs. 191-196.

${ }^{23}$ Castiella, A., La Edad del Hierro en Navarra y Rioja. Pamplona 1977, págs. 17-21.

${ }^{24}$ SAnChez, A. C. y UnzU, M., op. cit., págs. 62-64. 
como en el caso de San Quiriaco (moneda de Constantino) ${ }^{25}$. Donde sí hubo un asentamiento en época romana es en lbero. Hasta ahora los hallazgos han sido casuales, como la inscripción latina de SEVERA ${ }^{26}$, pero no cabe duda de que debió tratarse de un importante enclave, situado en la confluencia de los ríos Arga y Araquil, con un manantial termal que sin duda influyó en la elección del lugar de asentamiento ${ }^{27}$.

Otro núcleo importante de asentamientos pertenecientes a la Edad del Hierro se sitúa en Pamplona y su entorno, se trata de los poblados de Santa Lucia, Pamplona y Lezkairu-Malpaso.

La ocupación del poblado de Santa Lucía puede remontarse al Bronce Final, con un «taller al aire libre», para continuar durante el Hierro I, con la presencia de cerámica manufacturada, y el Hierro II, en que conocen la cerámica torneada celtibérica. Su vida terminará a la llegada de los romanos, como ocurre en los poblados cercanos de Leguín y Santo Tomás, en Echauri, y Sansol, en Muru-Astrain.

En cuanto al solar de la futura Pompelo ${ }^{28}$, ya estaba ocupado desde el Bronce Final o comienzos del Hierro I, continuando hasta la época romana, en que, tras la fundación de Pompeyo, debió constituirse en uno de los núcleos principales de los vascones, que absorvería la población de los lugares cercanos a ella.

El poblado de Lezkairu-Malpaso tuvo una vida más corta, que puede remontarse a la Edad del Bronce y llegar hasta el Hierro I ${ }^{29}$.

Es a escasa distancia de estos tres poblados donde se encuentra el manantial de Burlada, que hemos analizado más arriba. Resulta casi imposible de demostrar que fuera conocido por los habitantes de la zona, pero se encontraba al pie del cerro donde se hallaba el primitivo poblado de Pamplona, en la margen derecha del Arga, y equidistante de los asentamientos de Santa Lucía y Lezkairu ${ }^{30}$.

25 Castiella, A., op. cit, págs. 21-22.

26 Taracena, B., y Vazouez de PARga, L., "Excavaciones en Navarra. V. La Romanización", PV XXIV, 1946, págs. 429-430, inscrip. 31.

${ }^{27}$ El término lbero aparece en dos inscripciones dedicadas a divinidades acuáticas, procedentes de Tarragona y San Martin de Trevejo (Lusitania), ver Dupre, N., y Peréx, M. J., "Thermalisme et réligion dans le Nord de l'Hispania (des Pyrénées à l'Ebre)", Caesarodunum XXVI, 1992, págs. 151-169.

${ }^{28}$ Peréx, M. J., Los Vascones. Pamplona, Institución Príncipe de Viana, 1986, págs. 186215, con todos los datos aportados por las investigaciones de M. A. Mezquíriz.

${ }^{29}$ Castiella, A., op. cit., págs. 11-17.

30 También en Pamplona existen tres fuentes: de los Legañosos, del Hierro y la Teja, con propiedades medicinales, que no seria de extrañar que ya fueran utilizadas por sus primitivos habitantes. 
SOMONTANO RIOJANO

La última concentración de balnearios corresponde al somontano riojano, al pie de la ladera norte del Sistema lbérico, entre éste y la ribera del Ebro. Aquí se encuentran Arnedillo, Grávalos, La Pazana y Albotea (en La Rioja) y Fitero (en Navarra) ${ }^{31}$.

El balneario de Arnedillo se encuentra situado en un circo montañoso, en la margen derecha del río Cidacos. Sus aguas son cloruradas sódicas, hipertermales $\left(52,5^{\circ}\right)$. No hay noticias de la existencia de vestigios antiguos en el propio Arnedillo, pero en sus proximidades han sido localizados hasta cuatro poblados ${ }^{32}$. Se trata de «El Castejón» (entre Santa Eulalia Somera y Arnedillo), «El Castillejo» (entre Enciso y Navalsaz), «El Castillo» (entre Enciso y El Villar de Enciso) y "Corrales de Senoba» (entre Enciso y Garranzo). Por tratarse de una recogida de materiales de superficie y de una valoración sobre el terreno, las conclusiones son todavia provisionales, aunque parece coincidir en todos ellos su adscripción a la Edad del Hierro (cerámica a torno, molinos, muros, restos de viviendas, etcétera), desapareciendo en un momento impreciso que coincidiría con la presencia romana.

A estos poblados habría que añadir el de San Miguel de Arnedo, con cerámica a mano del Bronce Final y I Edad del Hierro, y abundante cerámica a torno, de la II Edad del Hierro, en el que se han identificado las plantas de tres viviendas (dos rectangulares y una circular) ${ }^{33}$.

En la Sierra de Peñalosa existen dos balnearios, el de Grávalos ${ }^{34}$, de aguas sulfurosas, y el de La Pazana (en el término de Cornago). El origen de este último se remonta a 1866, cuando el propietario de la finca del mismo nombre limpió la fuente de la que manaba agua de olor a sulfuro y que ya se conocia por haber sanado algunos animales ${ }^{35}$. Se dice que

${ }^{31}$ Arnedillo y Fitero son los únicos balnearios en funcionamiento en la región navarroriojana, ver AUQUE, L. F., et alii, "Análisis de los estados de equilibrio termodinámico en el reservorio de las surgencias termales de Fitero (Navarra) y Arnedillo "Rioja)", Revista de la Sociedad Geológica de España, 2 (1-2), 1989, págs. 125-132.

32 Pascual Mayoral, P. y Pascual González, H., "Nuevos yacimientos arqueológicos en el valle del Cidacos: Prejano, Navalsaz y Garranzo", I Coloquio sobre Historia de La Rioja, (Logroño 1982), Colegio Universitario de La Rioja, 1983, págs. 205-218.

${ }_{33}$ Castiella, A., op. cit., págs. 154-161.

${ }^{34}$ En la pared de los porches del Ayuntamiento se encuentra empotrada una lápida funeraria romana, datada a finales del siglo II o comienzos del siglo III; EspINosA, U., Epigrafia romana de La Rioja. Logroño, Instituto de Estudios Riojanos, 1986, págs. 87-88.

${ }^{35}$ Abad, F., La paz de la Pazana. Logroño, Ochoa, 1979, págs. 13-14. 
al levantar la tierra de los alrededores salieron restos de vasijas y vasos, lo que demostraba una utilización anterior. Desgraciadamente, ni se han conservado dichos objetos ni siquiera se hizo una somera descripción en el momento, por lo que nos es imposible saber sus características ${ }^{36}$.

El balneario de la Albotea se encuentra situado en la margen derecha del río Alhama (en el término de Cervera), a unos $3 \mathrm{~km}$ al sur de los Baños de Fitero.

Éstos se encuentran junto a la Peña del Baño, y sus aguas fueron analizadas en el año $1768^{37}$. Hay dos manantiales: los Baños Viejos o Palafox y los Nuevos o Balneario Bécquer. Eran conocidos desde 1146, como baños de Turungen, en que formaron parte de una donación llevada a cabo por el emperador don Alonso ${ }^{38}$. También se citan en el Cartulario de Fitero (1157) como «balneum de Caracallo» y en el Liber Jacobi ${ }^{39}$.

Pero sobre todo, fueron muy bien conocidos y utilizados en época romana, como lo demuestran los importantes restos todavía hoy a la vista. Se trata de una piscina circular con un diámetro, en su parte superior, de $2 \mathrm{~m}, \mathrm{y}$ una profundidad total de $1 \mathrm{~m}$. Hasta el fondo hay tres gradas que permitian a los bañistas estar cómodamente sentados con las extremidades inferiores sumergidas en el agua ${ }^{40}$. También se conserva la cisterna o castellum aquae, donde fluye y se capta el manantial. En la ladera del monte, por encima y próximos al castellum, se pueden observar restos de otras construcciones que aprovechan la roca natural como pared, completándola con sillares.

Entre los pocos materiales recuperados hay algunos fragmentos cerámicos muy pequeños y poco representativos (TSH de forma indeterminada, cerámica pigmentada y común).

Con relación a estos baños, tanto el de la Albotea como los de Fitero, no podemos dejar de mencionar el yacimiento de la Peña del Saco, que se encuentra situado entre ambos. Se trata de un asentamiento que se remonta a la Edad del Bronce, continuándose su ocupación durante la

${ }^{36}$ El agua, que brota de dos fuentes muy próximas, tiene un alto porcentaje de hidrógeno sulfurado, y una temperatura de $14^{\circ}$

${ }^{37}$ Se trata de aguas fuertemente mineralizadas y extremadamente duras, de facies clorurada sódica y sulfatada cálcica. Surgen a través de materiales de muy baja permeabilidad: yesos, carniolas, calizas, margas, areniscas y conglomerados del Triásico, Jurásico y Cretácico Inferior.

${ }^{38}$ GolcoeCHEA, A., «Hidroterapia y medicina popular vasca en el siglo XVIII», Cuadernos de Etnología y Etnografia de Navarra, 57. Pamplona 1991, pág. 113 (a partir de ahora CEEN).

${ }^{39}$ Mezquiriz, M. A., "Las termas romanas de Fitero", PV Anejo 3, 1986, págs. 539-554.

40 MezQuiriz, M. A., "Las instalaciones balnearias romanas de Fitero", PV Anejo 7, 1987, págs. $491-501$. 


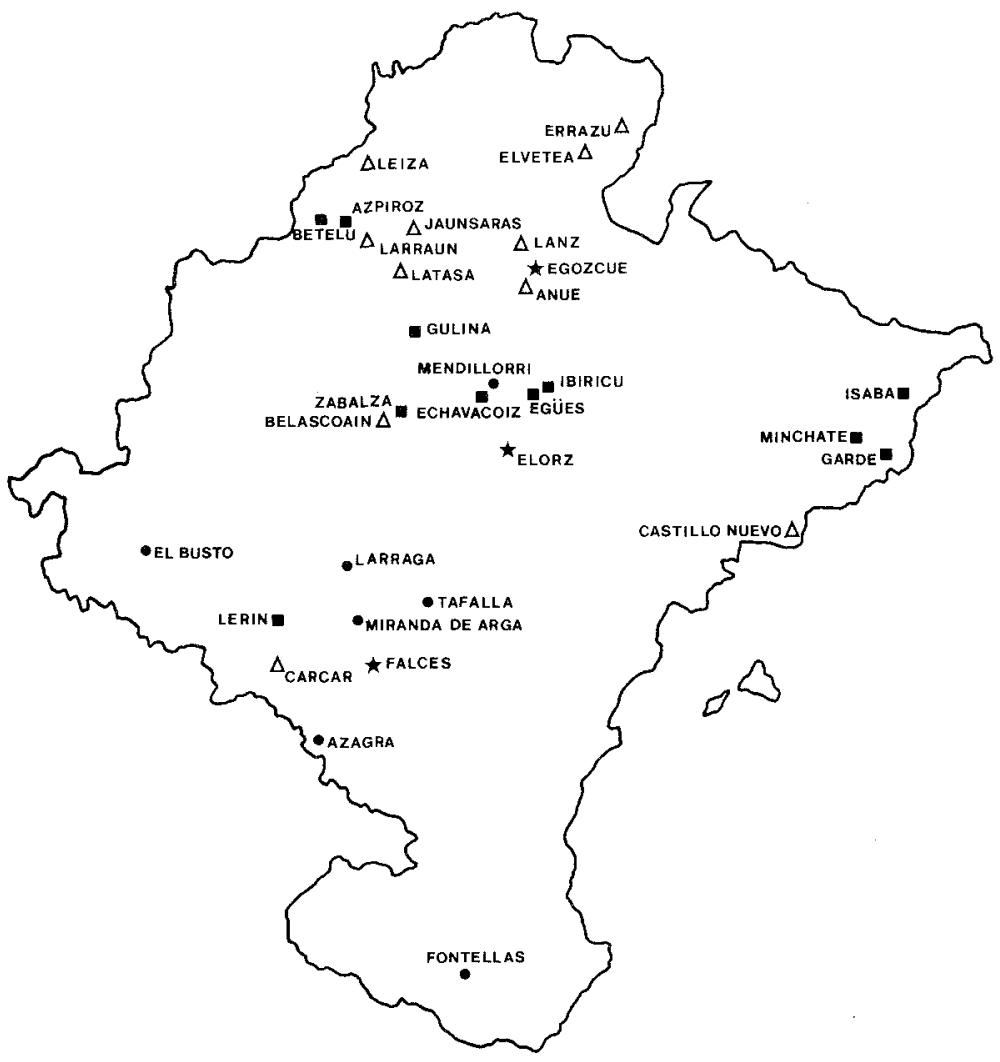

MEDICINA CREENCIAL

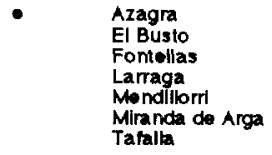

\section{MINERO-MEDICINALES}

$\begin{array}{ll}\text { SULFUAOSAS: } & \text { Azpiroz } \\ \text { Beielu } \\ \text { Echavacoiz } \\ \text { Eguids } \\ \text { Garde } \\ \text { Gulina } \\ \text { Ibiricu } \\ \text { Isaba } \\ \text { Lerin } \\ \text { Minchate (Roncal) } \\ \text { Zabaiza }\end{array}$

\begin{tabular}{|c|c|}
\hline $\begin{array}{c}\text { FERRUGINOSAS: } \\
\Delta\end{array}$ & $\begin{array}{l}\text { Anué } \\
\text { Belascoáin } \\
\text { Cárcar } \\
\text { Castlilo Nuevo } \\
\text { Elvetea } \\
\text { Errazu } \\
\text { Jaunsarás } \\
\text { Lelza } \\
\text { Lanz } \\
\text { Larraun } \\
\text { Latasa }\end{array}$ \\
\hline
\end{tabular}

SALINAS: Egozcue

$\star \quad$ Elort

Lám. 2. Relación de fuentes en Navarra con alguna propiedad caracteristica. 
Edad del Hierro ${ }^{41}$. Partiendo de un establecimiento humano de carácter pastoril, evolucionó hasta que se implantó en él la cultura celtibérica, consecuencia de la expansión bélica de los núcleos celtibéricos situados al Sur.

Uno de estos núcleos, situados en el término de Inestrillas, se corresponde con la ciudad celtibérica de Contrebia Leukade ${ }^{42}$, cuya cronología se remonta al siglo III a. C., llegando al siglo III d. C., siendo su momento de mayor desarrollo a comienzos del siglo $\|$ a. $\mathrm{C}$.

Hemos visto, por tanto, tres zonas bien diferenciadas, desde el punto de vista del poblamiento, que obedecen, además de a criterios geográficos, como altitud o clima, a distintas etapas de la evolución histórica de sus habitantes.

Las estribaciones Occidentales del Pirineo debieron estar relativamente poco pobladas, de ahí que la mayoria de los vestigios correspondan a establecimientos temporales o estacionales, y sobre todo a enterramientos relacionados con movimientos de trashumancia. Es por ello por lo que en las zonas de pastos de alta montaña son tan abundantísimas las construcciones dolménicas. Estos pastores trashumantes, y sus ganados, debieron conocer las propiedades de los manantiales que aqui estudiamos (Alsasua, Betelu, Elgorriaga y Arive), pues todos ellos se hallan en los caminos de paso obligado hacia dichos pastos.

Cuando atraviesan estas tierras, a comienzos del primer milenio, las primeras oleadas de gentes indoeuropeas, celtas, se van a producir importantes cambios, en gran medida en función de los lugares de asentamiento. Éstos tienen lugar en la zona intermedia de Navarra y, sobre todo, en la ribera del Ebro, en ambas márgenes, donde se encuentran las tierras más aptas para la agricultura, mientras que en la cuenca de Pamplona seguiría siendo importante el pastoreo ${ }^{43}$.

\footnotetext{
"1 TaRAcena, B. y VAzquez de PARga, L.., “Exploración del poblado celtibérico de Fitero", PV 23, 1946, págs. 1-13; Muluquer, J., «Notas estratigráficas del poblado celtibérico de Fitero (Navarra)", PV 100-101, 1965, págs. 331-334, y CASTiELLA, A., op. cit., págs. 168-183.

42 Hernández Vera, J. A., Las ruinas de Inestrillas. Estudio arqueológico. Logroño, Instituto de Estudios Riojanos, 1982, 296 págs.

${ }^{43}$ Es a esta zona, comprendida entre el Pirineo y el valle medio del Arga, a la que debió corresponder el territorio originario de los vascones, que recibió importantes aportes indoeuropeos, tanto en el ritual funerario, como es la práctica de la incineración (cromlechs), como en la toponimia (el caso de Ulzama).
} 
Pero la zona más desarrollada, coincidiendo con la II Edad del Hierro ${ }^{44}$, se corresponde con el Valle Medio del Ebro. En su margen derecha, la zona que aquí estudiamos es la comprendida entre los ríos Cidacos y Alhama ${ }^{45}$. Es en la confluencia de este último con el Ebro donde, en el año 178 a. C., T. Sempronio Graco funda la ciudad de Graccurris. Esta fundación tan temprana y en donde todavía no habían tenido lugar muchos contactos con Roma, no cabe duda que se hizo en función de su situación estratégica por su fácil acceso, siguiendo el curso del Alhama, a la zona más fuerte de Celtiberia ${ }^{46}$, lo que permitía vigilar y atacar con mayor rapidez a los arévacos.

No cabe duda de que las guerras celtibéricas fueron determinantes en la desaparición de muchos de los poblados que hemos visto más arriba, del mismo modo que la temprana presencia de los romanos en estas tierras debió suponer el pronto acondicionamiento de los manantiales termales de Fitero, que son los únicos de los que, hasta el momento, tenemos claros vestigios de su utilización en época imperial.

Por todo ello, creemos que se hace necesario llevar a cabo planes conjuntos de investigación que abarquen aspectos geológicos, arqueológicos, e incluso, médicos, en aquellos lugares en los que confluyan manantiales termominerales y yacimientos arqueológicos, para poder llegar a establecer, con la mayor precisión posible, el proceso de su utilización a lo largo de la Historia ${ }^{47}$.

No pretendemos, por tanto, establecer aqui un cierto determinismo en la localización de los asentamientos en función de los surgimientos de

${ }^{44}$ Castiella, A., «Nuevos datos sobre la Protohistoria navarra», PV Anejo 7, 1987, págs. 229-238.

${ }^{45}$ En el tiempo fue territorio pelendón, luego arévaco, todo él englobado en el ámbito celtibérico.

${ }^{46}$ Hernández Vera, J. A. y Casado, P., "Graccurris, la primera fundación romana en el Valle del Ebro", Symposium de ciudades augusteas. Zaragoza 1976, vol. II, págs. 23-31.

${ }^{47}$ No queremos dejar de señalar aqui la coincidencia en la localización de yacimientos junto a todas las salinas atestiguadas en Navarra. Así, Arteta y Egozcue: dólmenes (Neolitico/Edad del Bronce), Falces (romano), Javier (Neolítico/Bronce/Hierro y romano), Lerín (Hierro y romano), Mendavia (Bronce/Hierro y romano), Obanos (taller al aire libre del Neolítico), Salinas de Oro (Edad del Hierro y eremitorio medieval), y Tirapu (taller al aire libre de la Edad del Bronce), datos procedentes del Archivo Documental del Museo de Navarra, Pamplona.

También cabria reseñar aqui la relación de fuentes cuyas aguas son conocidas por alguna propiedad caracteristica. Dado su elevado número hemos considerado interesante plasmar su localización en un mapa. Un estudio reciente puede encontrarse en la Gran Enciclopedia Navarra, Pamplona, Caja de Ahorros de Navarra, 1990, voz "agua», y en GolCOECHEA, A., "Hidroterapia y medicina popular vasca en el siglo XVIII», CEEN, 57, 1991, págs. 105-118 [Lámina 2]. 
aguas mineromedicinales, pues tergiversaría los mapas de distribución del poblamiento ${ }^{48}$, sino que, como decíamos al principio, se trata de una mera hipótesis que permite poner de manifiesto ciertas relaciones, a partir de las cuales se puede empezar a investigar en lugares concretos.

RESUMEN

Hasta el momento, la mayoria de las investigaciones sobre la utilización de las aguas termales y medicinales en la Antigüedad, se ha centrado en el estudio de la epigrafía referida al culto a las aguas, casi siempre fuera de contexto, y en los centros termales datados en época romana. Una de las mayores dificultades radica en establecer el momento del comienzo de su utilización. Para ello proponemos, como primer paso, el estudio de aquellos yacimientos que se encuentran próximos o junto al manantial, referidos, principalmente, a la Edad del Hierro. Aquí presentamos, a título de ejemplo, los localizados en Navarra y Rioja.

\section{ABSTRACT}

Till now, the majority of the research about the use of thermal and medicinal waters during Antiquity, has been concentrated in the study of the epigraphy, refered to the cult to these waters (almost always out of context), and in the thermal centers during Roman times. One of the main difficulties is to establish the moment of the begining of its use. For that reason, we propose, as a first step, the study of the sites which are close to the spring water, mainly refered to the Iron Age. Here below, we present, as an exemple, those which are located in Navarra and Rioja (Spain).

48 SAYAS, J. J, «El poblamiento romano en el área de los Vascones», Veleia 1. Vitoria 1984, págs. 289-310; Llanos, A., "La Edad del Hierro y sus precedentes, en Álava y Navarra", Munibe 42. San Sebastián 1990, págs. 167-179. 